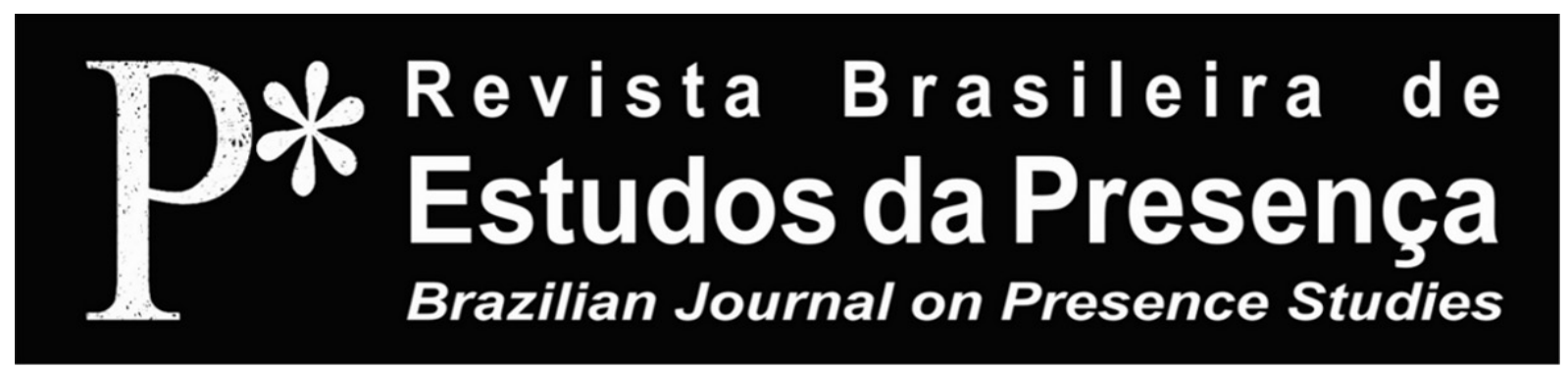

DOI - http://dx.doi.org/10.1590/2237-266041937

ISSN 2237-2660

\title{
Performance e Documento, ou 0 que chamamos por esses nomes?
}

\author{
Lúcio José de Sá Leitão Agra \\ Pontifícia Universidade Católica de São Paulo - PUC-SP, São Paulo/SP, Brasil
}

RESUMO - Performance e Documento, ou o que chamamos por esses nomes? - O artigo ensaia a discussão entre a questão do documento na performance e a perspectiva que desarma a lógica do colonizador na produção dessa arte em países periféricos. Sugere a possibilidade de se pensar os desafios das instituiçóes de apoio/arquivo da obra de arte nesse contexto e em face das perspectivas da arte contemporânea, tomando como princípio norteador a ideia de que há uma produção de performance brasileira que escapa ao entendimento forjado nos centros de prestígio internacionais que norteiam o mercado artístico.

Palavras-chave: Performance. Documento. Performatividade. Arquivo. Memória.

ABSCTRACT - Performance, Documentation, or what we call by these names? - This essay makes an effort to discuss the question of performance art documentation, under the point of view of the deconstruction of colonizer's logic as a result of the practice of this art in peripheral countries. The essay suggests the possibility to think about challenges put against institutions in charge to archive and support the work of art, Regards the perspectives concerning contemporary art. It takes, as a guiding principle, the idea that there is a production of Brazilian performance which gets out of the common understanding forged in prestigious centers of the international art market.

Keywords: Performance. Document. Performativity. Archive. Memory.

RÉSUMÉ - Performance, Documentation, ou qu'entend-on par ces termes? - L'article apporte une réflexion sur la question de la documentation dans l'art de la performance, s'inscrivant dans une perspective qui cherche à déconstruire la logique du colonisateur dans la production de cet art dans des pays périphériques. Le texte propose d'envisager les défis qui se posent aux institutions chargées de donner support et d'archiver le travail artistique dans le contexte de l'art contemporain, soutenant l'idée qu'il existe une production performatique brésilienne qui échappe à la compréhension forgée dans les grands centres urbains qui commandent le marché de l'art international et prestigieux.

Mots-clés: Art Action. Documentation. Performativité. Archives. Mémoire. 
Philip Auslander, em seu famoso artigo The performativity of performance documentation (2006), faz uma distinção, desde entáo muito empregada, entre atitudes de registro da performance ${ }^{1}$ que poderiam ser documentais ou teatrais. Servindo-se do exemplo de dois artistas clássicos, Chris Burden e Yves Klein e suas respectivas performances, Shoot (1971) e Salto no Vazio (1960), o autor observa que a primeira tem registros factuais de um evento efetivamente acontecido, enquanto a segunda é uma fotomontagem que não corresponde a um fato real.

A categoria "documental", segundo Auslander, “[...] representa o modo tradicional de conceber a relação entre a arte da performance e sua documentação" (Auslander, 2006, p. 1). O que sempre se supóe é que esta é, ao mesmo tempo, um registro (para reperformances futuras) e uma prova de que o ato efetivamente ocorreu. No Brasil, onde temos uma excelente história de críticas ao estatuto documental da fotografia, nem precisamos da citação que Auslander faz de Kathy O'Dell para concluir que os dois aspectos são falíveis (e não apenas a reconstrução, como assinala a autora citada). Como nota bem Auslander, o estatuto ontológico da ação, que precede o documento, é onipresente na história da Body Art dos anos 1960 e 1970.

Náo precisou muito tempo para que a performance - e seus estudos, derivados dos questionamentos pós-estruturalistas - fizessem a serpente morder o próprio rabo $^{2}$. A partir de certo ponto, toda a performance passou a ser também um reenactment. É de se pensar que a própria noção de "comportamento restaurado" - como é comumente traduzida a ideia de Schechner, originalmente pensada para a sua concepção de performance, bastante ampla - fosse também ela relida e traduzida como parte da descriçáo desse fenômeno (Schechner, 2006, p. 29; Taylor, 2012, p. 22)3.

Convém, entretanto, lembrar que o argumento documental - e não conscientemente parodístico ou parafrástico, como seria conveniente falar no pós-moderno - foi justamente aquele evocado por Marina Abramovic, nas suas 7 easy pieces (2005), um dos exemplos do documental mencionados por Auslander. Mas esse argumento, no caso dela, partia da crítica à impossibilidade do registro, como se ecoasse a máxima já conhecida na tradução de poesia: somente poetas são capazes de traduzir outros poetas. Uma performer experiente como Abramovic é que reuniria as condições de reconstruir para coraçóes, olhos e mentes que não viram os originais a forma pela qual as per- 
formances de seus amigos, que abandonaram o barco, efetivamente aconteceram. O vídeo ou as fotos seriam eminentemente falíveis ${ }^{4}$.

Ainda neste aspecto documental, Auslander menciona o que chama de "sofisticada análise", levada a cabo por Amelia Jones, cujos argumentos enfatizam a mútua dependência entre o documento e a performance, o que é evidente em artistas como Cindy Sherman, produtora de uma linhagem específica que podemos chamar de fotoperformance (não só no caso de retratos, mas também da presença do artista diante da câmera). Tal prática pode ser vista exemplarmente na obra de Francesca Woodman; ou, ainda, na Bienal recente (2012), podemos pensar nos casos de Hans Eijkelboom, Bas Jan Ander, Jirí Kovanda, Sigurdur Gudmundsson e Tehching Hsieh, todos documentais por vários aspectos e, a partir principalmente do último, as fotografias de Sofia Borges (Pérez-Oramas et al., 2012). $\mathrm{O}$ mesmo também se pensaria a propósito do trabalho de Carlos Monroy - Monroy's performance service No.1 - Sr Kosuth, o que você faria? - recentemente apresentado no Paço das Artes de Sáo Paulo5. O que Jones chama de "mútua suplementaridade" (apud Auslander, 2006 , p. 2) recai, entretanto, na foto como registro pois, como nota Auslander, é esse o argumento que Jones usa para defender sua escritura sobre eventos dos quais não foi testemunha.

$\mathrm{Na}$ verdade, o acréscimo que fiz acima já conduz o problema para a segunda categoria sugerida por Auslander, a teatral. Nela, ele inclui desde o autorretrato como Rose Sélavy de Duchamp, a própria Sherman até os filmes de Matthew Barney. Confesso que implico com o nome teatral, náo só pelo motivo etimológico - o lugar de onde se vê, uma origem provável da própria mística fotográfica -, mas também pelo aspecto de encenação ou ficcional que normalmente a instância teatral carrega consigo.

Os problemas conhecidos dessa instância conduziram os rumos de um teatro contemporâneo no qual noções como atuação, representação, espetáculo, drama - e mesmo performance, no sentido instrumental que lhe deu o teatro, em diversas ocasióes - passaram a ser parte fundamental do debate e da própria produçáo artística. $\mathrm{O}$ dilema da ficção, por outro lado, na fotografia, foi discutido durante todo o século XX (o mesmo, quero crer, valendo para o cinema) com a questáo do registro direto, o fotojornalismo, a montagem da cena fotográfica etc. A discussão tem um brilhante comentário no trabalho 
de Arlindo Machado no inestimável livro A ilusão especular - introdução à fotografia (1984), lamentavelmente ausente das livrarias há tantos anos. Nesse livro, Arlindo historia o processo de construção da ilusão de realidade da fotografia, cujo aparato deriva da ilusão de profundidade produzida pela invençáo renascentista da cammera obscura. A fotografia que busca a intensidade do acontecimento vivido - sobretudo quando tem o famoso apelo bumano - enfrentou a contrapartida do construtivismo fotográfico, consciente de seu aparato e curioso investigador das formas pelas quais a luz recorta e desenha os objetos. No meio desse dilema, complicado pela disseminaçáo da foto colorida e o desenvolvimento das técnicas de pós-produção/ manipulação digital, trafega todo o universo da discussão sobre os estatutos ontológicos da fotografia - e o do filme - no século XX e XXI e suas implicaçóes semióticas e filosóficas.

Auslander acerta ao considerar que, "[...] de uma outra perspectiva", (fora da discussão ontológica) "[...] as duas categorias parecem ter muito em comum. [...] em ambos os casos as duas imagens foram apresentadas para uma câmera" (2006, p. 3). O que fica bem claro é a presença do aparato modificador.

Essa presença é mais sentida, diria eu agora, na medida de sua própria ausência. O caso que quero comentar de passagem, de artistas mexicanos fascinados pela performance e que reperformaram algumas açóes dos anos 1970 a partir de fotos - o único material de que dispunham -, dá um outro sentido ao ao vivo dessa arte, pois não só produziram seu próprio discurso sobre a performance importada (nesse caso, predominantemente estadunidense), como também demonstraram um sentido de vida contra a morte que o documento pode ter (Clausen, 2010) ${ }^{6}$.

Guzman e Ortega são autores de um vídeo de 1994 intitulado Remake. Segundo os próprios artistas, citados por Barbara Clausen, "[...] antes de fazer Remake, tínhamos pesquisado os dados existentes sobre certos artistas que praticaram a performance nos anos 70 [...]. As referências vinham de revistas americanas e europeias, ou de livros de amigos. A maior parte dos registros em vídeo, disponíveis em outros países, eram desconhecidos no México" (apud Clausen, 2010, p. 19)7. O propósito não teria sido a reconstrução de tais açóes, mas antes, como observa a autora, "[...] propor uma interpretação dessas açóes que, assim, tornavam-se suas". Tratava-se de clássicos da performance como Glass (1974), de Paul McCarthy (retomada nas 7 peças de Ma- 
rina Abramovic) ou Self-portrait as a Fountain (1966-67), de Bruce Naumann - para citar alguns exemplos. Clausen, ainda, prolonga sua especulação, sustentando que eles assumem "[...] a tarefa dialética entre a encenação do documentário e o documentário da encenação". Segundo ela, o vídeo seria um exemplo singular de apropriação "[...] de elementos exteriores integrados à sua própria versão". Ao comentar o fato de que, ao lado de releituras de McCarthy, Naumann e Fox, os autores ainda acrescentaram um trabalho próprio à sequência do vídeo, Clausen afirma: "O êxito de Remake é emblemático do crescimento da arte latino-americana durante os anos 90, um movimento engajado na sensibilidade conceitual e performativa contemporânea, aparentada àquela dos anos 70". "Tanto na prática como na teoria”, diz a autora, há uma tomada de consciência do "[...] estatuto ontológico da performance como construção, fundada em sua natureza contingente". Esse debate, observa Clausen, ainda, em uma nota, envolveu Philip Auslander e Peggy Phelan e hoje é visto como uma das questóes centrais dos estudos da performance (Clausen, 2010, p. 19 e S). Evidentemente, diversos fios soltos poderiam ser derivados dessa situação, mas o que interessa principalmente aqui é comentar as consequências da própria subversáo do conceito de documento que se insinua nesse exemplo e como, ao mesmo tempo, ele aponta para o problema da hegemonia dos discursos emanados dos grandes centros e as estratégias - poderíamos já dizer - antropofágicas que os periféricos hão de engendrar em meio às potências museológicas.

Ao mencionar exemplos como o de Gina Pane, que considerava o fotógrafo parte integrante de seu trabalho, Auslander tangencia o problema que ganha contornos muito mais sutis - e, a meu ver, interessantes - quando se trata de falar destes artistas em países periféricos, distantes do fluxo de desenvolvimento infindável dos mecanismos de registro. Daí se percebe a dimensão política de sites como o ubuweb (http://www.ubuweb.com), cujo enfrentamento das políticas de direito autoral torna possível a apropriação das obras por parte de artistas em situação de exclusão. Em contrapartida, a devoração dos modelos importados acaba por gerar formas de criação que póem em evidência padróes performáticos presentes nestas - por assim dizer - civilizaçóes periféricas que revogam o próprio conceito de ao vivo construído como crítica do formalismo artístico europeu. Não seria, então, este conceito - o da performance como sendo unicamente uma arte da presença - o modo pelo qual os criadores da 
metafísica dualista de falso/verdadeiro lograram entender o momento em que a mesma se rompeu?

Náo teriam sido as periferias do mundo - onde mais prospera a arte da performance e onde a performance desde sempre existiu com inúmeras outras denominaçóes - aquelas que já de partida não se deixam comover pela falsa oposição entre ficção e realidade? Não diziam G.G. Márquez ou Octavio Paz que, no mundo latino-americano, a realidade parece mais absurda que a própria ficção? Oswald de Andrade disse, com todas as letras, em seu Manifesto Antropofágico, que já tínhamos a psicanálise. Parece-me que, de contrabando, isso implica também o surrealismo, já que possuíamos em nossa história um renegado Qorpo-Santo ${ }^{8}$.

Autores tão diferentes como o performer e teórico da performance polonês Jan Swidzinski, com seus oitenta e tantos anos, ou a chinesa Chin Tao Wu, no seu comentário ao mercado global de arte, são todos coincidentes na percepção de que há outras perspectivas de observação que vêm desafiando o pensamento ocidental hegemônico. Renato Ortiz, Jesus Martin Barbero, Nestor Garcia Canclini, Amálio Pinheiro, Milton Santos, Vandana Shiva, Laymert G. dos Santos, a lista cresce exponencialmente do lado dos mexicanos, brasileiros, uruguaios, bolivianos, paquistaneses, argelinos (como Derrida) e por aí vai'.

Com isso, quero dizer também que o brilhantismo do texto de Auslander não alcança uma dimensão experiencial que o olhar deslocado pode promover. Evocando a radical virada epistemológica sugerida por Eduardo Viveiros de Castro com a questão do perspectivismo ameríndio ${ }^{10}$, como seria possível que, no interior mesmo da afluente indústria da imagem técnica, se vislumbrasse seu caráter falacioso e a própria noção de verdade passasse a ser, nesse mesmo contexto, mas filosoficamente falando, a principal derrocada cognitiva, juntamente com o declínio do colonialismo explícito?

Entretanto, se ainda acompanharmos Auslander mais adiante, vemos que mesmo ensaístas que ele cita, como Don Slater ou Kathy O’Dell, não estão tão desatentos ao caráter ficcional do documento. $\mathrm{O}$ primeiro defende a ideia de que a fotografia "[...] no final das contas substitui a realidade dos documentos", enquanto a segunda afirma que a "[...] arte da performance é o equivalente virtual de suas representações" (Auslander, 2006, p. 3). Acho que, com isso, fica nítida 
a utilidade dessa arte - e do pensamento que ela produz - naquele contexto periférico que mencionei há pouco.

A observação seguinte de Auslander serve para meditarmos um pouco quanto àquele aspecto do ficcional no teatro:

No fim, a única diferença significativa entre os modos documentário e teatral da documentação da performance é ideológica: a crença de que no primeiro modo o evento é 'encenado' para uma plateia imediatamente presente e sua documentação é secundária, registro suplementar de um evento que tem sua integridade anterior. Como demonstrei aqui, esta crença tem ínfima relação com as circunstâncias atuais sob as quais as performances são feitas e documentadas (Auslander, 2006, p. 34).

As conclusóes de Auslander, resumidas na frase "[...] o ato de documentar um evento como performance é que o constitui como tal" (Auslander, 2006, p. 34) passam por uma analogia da fotografia com a noção tradicional de performativo tal como originalmente proposta por Austin (1962), isto é, como um discurso que faz acontecer. Não deixa de ser curioso o raciocínio que desloca o performativo da ação propriamente dita para o registro, mas devemos atentar para o fato de que o autor luta para inserir o mesmo na própria ação, o que não é pouco. Eu diria que se trata de um esforço modernista como o que chamou a atençáo para a forma visual e gráfica do texto na poesia moderna. A essa conclusão Auslander chega depois de avaliar uma performance de Vito Acconci (Photo Piece, 1969; com uma rápida busca pela Internet, é possível achar as 12 fotos da performance), cuja testemunha teria sido tão somente uma câmera fotográfica.

Conforme ele observa ainda, o virtuosismo do performer não consiste em fazer parecer real, mas na eficácia do ato "metacomunicativo" (Auslander, 2006) (termo que ele traz de uma proposição de Richard Bauman) de dizer "ei, olhe pra mim, eu estou aqui e quero demonstrar algo que pode ser interessante". Audácia e originalidade constituem-se em fatores que, de passagem, podem explicar o gosto pelo risco na performance (e na poesia).

Sendo instâncias tão inapreensíveis e sujeitas ao contexto, essas, por assim dizer, características da performance refreiam o impulso de institucionalização pela via do documento que, em tese, está empobrecido do acontecimento.

Dar nome a essa situação, tratando-a como efêmera, é apenas dar um nome. O que interessa saber é como essa espécie de ação- 
contra-registro se produz em instâncias periféricas nas quais as instituiçóes encarregadas da guarda e preservação vivem elas mesmas a precariedade que é fator conceitual da performance.

Fará sentido falar de institucionalização da performance - por via do documento - quando se trata da precária dotação de recursos para isso que conhecemos historicamente no Brasil? Depois da Missão Francesa, em quantas ocasióes a cultura foi a prioridade dos governantes por aqui (ainda que prioridade, nesse caso, signifique tão somente estratégia de ocupaçáo para a elite colonizadora)?

As perguntas que se faz Auslander a respeito da ausência de caráter metacomunicativo na performance de Acconci - ao se fotografar sem testemunhas ${ }^{11}$, ele joga para a foto toda a interação que normalmente se dá em cumplicidade ao vivo com uma plateia - poderiam ser pensadas, a meu ver, como já mencionei acima, num plano que venho chamando de descentrado e que corresponde ao olhar periférico no mundo atual. Um exemplo já seria aquele comentado por Clausen (ver acima).

Gostaria, para finalizar, de tomar algumas palavras do texto de Suely Rolnik, Geopolitica da cafetinagem (2006), que formulam perguntas a partir da constatação do surgimento de novas questóes políticas na arte dos anos 1990, no Brasil:

Algumas perguntas se colocam diante da emergência deste tipo de temática no território da arte. $\mathrm{O}$ que questóes como essas vêm fazer aí? Por que elas têm sido cada vez mais recorrentes nas práticas artísticas? E, no Brasil, por que elas só aparecem agora? E qual o interesse das instituiçóes em incorporá-las? Vou esboçar, aqui, algumas vias de prospecção para o enfrentamento destas perguntas (Rolnik, 2006, p. 1).

Prefiro ficar apenas com a formulação da pergunta que, para mim, soa como uma espécie de estratégia de advertência para qualquer debate: a quem interessa discutir o problema da documentação da performance agora? E, anteriormente a isso, mas totalmente conjugado: o que temos chamado de performance no Brasil?

Com essas perguntas inspiradas por Suely Rolnik e por Liliana Coutinho, encerro sugerindo que temos que nos interrogar, no Brasil em particular, e na América Latina em geral, quais são as políticas que fizeram assomar ou sucumbir o próprio ato da performance, já que sabemos que ele pode ser, na memória, tanto documental como teatral ou ambos. 


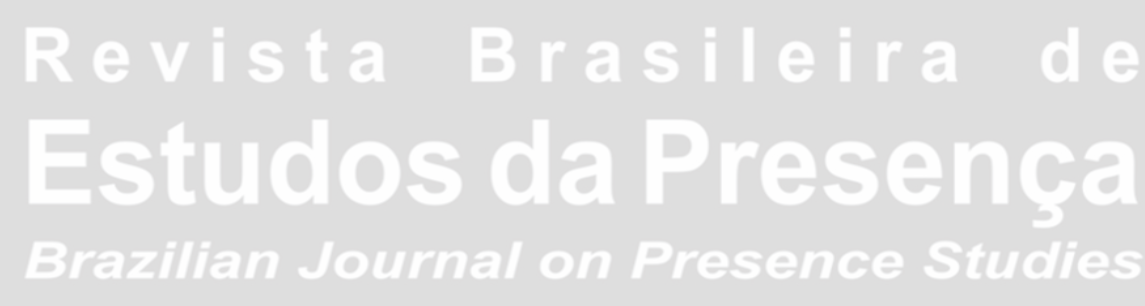

\section{Notas}

${ }^{1} \mathrm{O}$ termo performance vem admitindo vários outros de acordo com os lugares de uso. Durante muito tempo, empregou-se o termo live art na Inglaterra, action nos francofônicos e arte accion entre os hispânicos. Mais recentemente, o termo de maior uso é performance art para diferenciar de outros sentidos que a palavra tem no inglês. Eu pessoalmente milito para a manutenção do termo performance pois performance arte, em português, é uma sintaxe alheia ao nosso idioma.

2 Trata-se da tradicional imagem mitológica da serpente que morde o próprio rabo Ourobouros ou Urobóros.

3 O termo "restored behavior" é frequentemente traduzido como "comportamento restaurado". As traduçóes de Schechner que circulavam no meio acadêmico brasileiro eram precárias até a recente edição de Performance e Antropologia, de Richard Schechner (Ligiéro, 2012). A data dessa publicação coincide com o livro citado de Diana Taylor, que esclarece a noção em espanhol: "[...] performance es comportamento reiterado, re-actuado, o re-vivido" (Taylor, 2012, p. 22). Para afirmar isso, a autora vale-se de uma citação de Schechner que explica que a "performance is twice-behaved behavior". Isto é, trata-se de um comportamento reiterado, espécie de repetição de uma ação que já foi feita e assim é reconhecida. Convenha-se que essa ideia está mais próxima do que vulgarmente conhecemos como representar ou mesmo atuar e que se distancia de restaurar, que, no português, referese mais frequentemente a "reformar algo antigo ou fazer esse algo retornar a uma suposta condição original". O meu entendimento pessoal é que o que Schechner propóe seria uma outra forma de descrever a clássica situação cênica. Mas o que me parece interessar para a performance propriamente dita é o caráter de re-encenaçáo (reenactment) que já estaria implícito em todo ato desse tipo.

${ }^{4}$ Disponível em: <http://en.wikipedia.org/wiki/Seven_Easy_Pieces>. Acesso em: 19 ago. 2013.

5 Disponível em: <http:/www.pacodasartes.org.br/temporada-de-projetos/2012/artistas/ carlos_monroy.aspx>. Acesso em: 19 ago. 2013.

${ }^{6}$ Os artistas comentados são Daniel Guzman e Luis Felipe Ortega.

7 Disponível em: <http://www.luisfelipeortega.com/lfo/projects/36/191-remake.html>. Acesso em: 19 ago. 2013.

8 "Da Revolução Francesa ao Romantismo, à Revolução Bolchevista, à Revolução surrealista e ao bárbaro tecnizado de Keyserling. Caminhamos" (Andrade, 2011 [1928], p. 68-69).

9 Jan Swidzinski observa, no seu L'art et son contexte: "O que caracteriza esse movimento é que é mais fácil encontrar um festival internacional [de performance] em lugares periféricos tais como Romênia, Eslováquia (Nové Zamky) ou Coréia que nos Estados Unidos. A performance traça uma nova carta de açóes artísticas diferente daquelas de outros tempos" (Swidzinsky, 2005, p. 135).

${ }^{10}$ Ver Encontros, de Eduardo Viveiros de Castro (Sztutman, 2007).

${ }^{11}$ A descrição da performance, citada por Auslander: "Segurando uma câmara posta distante de mim e pronta para disparar, enquanto caminho por uma linha contínua em uma rua da cidade. Tento náo piscar. Cada vez que pisco: uma foto". No original em inglês: "Holding a camera, aimed away from me and ready to shoot, while walking a continuous line down a city street. Try not to blink. Each time I blink: snap a photo" (Auslander, 2006, p. 4). 


\section{Referências}

ANDRADE, Oswald de. A Utopia Antropofágica. São Paulo: Globo, 2011.

AUSLANDER, Philip. The Performativity of Performance Documentation. PAJ - A Journal of Performance and Art, Nova York, MIT Press, v. 28, n. 3, p. 1-10, set. 2006.

AUSLANDER, Philip. A performatividade da documentação de performance. ¿¿Hay en Portugués?, Florianópolis, Universidade do Estado de Santa Catarina, n. 2, s.p., 2013. Tradução: Regina Melim e equipe. Disponível em: <http://www.hayenportugues.blogspot.com. br/>. Acesso em: 19 ago. 2013.

AUSTIN, John Langshaw. How to do Things with Words - the William James Lectures delivered at Harvard University in 1955. Oxford: Clarendon Press, 1962.

CLAUSEN, Barbara. Archives of Inspiration. Ciel Variable - Art Photo Médias Culture - Performance, Montreal, Les Productions Ciel Variable, v. 86, s.p., outono 2010.

COUTINHO, Liliana. De que falamos quando falamos de performance. Marte, Lisboa, Associação dos Estudantes de Belas Artes/Universidade de Lisboa, n. 3, s.p., 2008.

LIGIÉRO, Zeca (Org.). Performance e Antropologia de Richard Schechner. Rio de Janeiro: Mauad X, 2012.

MACHADO, Arlindo. A Ilusão Especular - introdução à fotografia. São Paulo: Brasiliense, 1984.

PEREZ-ORAMA, Luis. Exhibition Guide - 30th Bienal de São Paulo - The Imminence of Poetics. São Paulo: Fundação Bienal de São Paulo, 2012.

ROLNIK, Suely. Geopolítica da Cafetinagem. Disponível em: <http://transform.eipcp.net/ transversal/0507/rolnik/pt>. Acesso em: 19 ago. 2013.

SCHECHNER, Richard. Performance Studies - an introduction. 2. ed. New York: Routledge, 2006.

SWIDZINSKI, Jan. L'Art et son Contexte - au fait, qu'est-ce que l'art? Québec: Inter, 2005.

TAYLOR, Diana. Performance. Buenos Aires: Asunto Impresso, 2012.

VIVEIROS DE CASTRO, Eduardo. Encontros. Organização: Renato Sztutman. Rio de Janeiro: Azougue, 2008.

WU, Chin Tao. Privatizaçáo da Cultura. São Paulo: SESC-SP/Boitempo, 2006.

Lúcio Agra é professor, pesquisador e artista da performance. É professor na graduação em Comunicação das Artes do Corpo da Pontifícia Universidade Católica de São Paulo PUCSP, onde também lidera o Grupo de Estudos da Performance. É presidente da Associação Brasil Performance (BrP) com sede em São Paulo. Doutor em Comunicação e Semiótica pela PUC-SP, autor de vários artigos publicados no país e no exterior. Seu livro mais recente é Monstrutivismo - reta e curva das vanguardas, pela editora Perspectiva (2010).

E-mail: lucioagra@gmail.com

Recebido em 04 de setembro de 2013 Aceito em 18 de outubro de 2013 